九州大学学術情報リポジトリ

Kyushu University Institutional Repository

\title{
How Lubricant Plays a Role in the Heat Pump System
}

\author{
Yang Changru \\ Department of Energy and Environmental Engineering, Interdisciplinary Graduate School of \\ Engineering Sciences, Kyushu University
}

Takata, Nobuo

Department of Energy and Environmental Engineering, Interdisciplinary Graduate School of Engineering Sciences, Kyushu University

\section{Kyaw Thu}

Department of Energy and Environmental Engineering, Interdisciplinary Graduate School of Engineering Sciences, Kyushu University

Miyazaki, Takahiko

Department of Energy and Environmental Engineering, Interdisciplinary Graduate School of Engineering Sciences, Kyushu University

https://doi.org/10.5109/4372279

出版情報：Evergreen. 8 (1)，pp.198-203，2021-03. 九州大学グリーンテクノロジー研究教育センター バージョン：

権利関係 : 


\title{
How Lubricant Plays a Role in the Heat Pump System
}

\author{
Yang Changru ${ }^{1, *}$, Nobuo Takata ${ }^{1}$, Kyaw Thu ${ }^{1,2}$, Takahiko Miyazaki ${ }^{1,2}$ \\ ${ }^{1}$ Department of Energy and Environmental Engineering, IGSES, Kyushu \\ University, Postal 816-0811, Japan \\ 2 International Institute for Carbon-Neutral Energy Research, Kyushu University, \\ Postal 816-0811, Japan
}

*Author to whom correspondence should be addressed: E-mail: yang.changru.125@s.kyushu-u.ac.jp

(Received November 5, 2020; Revised March 26, 2021; accepted March 26, 2021).

\begin{abstract}
The lubricant, which is considered as the necessary part inside the compressor, not only affects the operating efficiency of the compressor but also has interaction with refrigerant. To study the effect of lubricants on the improvement of heat pump performance, this paper investigated the types and the viscosities of lubricants that are chosen to apply in the heat pump cycle. The influence of lubricants was explained from three aspects: the interaction with refrigerants, the effect on the compressor, and the impact on the system performance, which may make some contribution to the development of new lubricant oils.
\end{abstract}

Keywords: lubricant, heat pump, system performance

\section{Introduction}

Compressors have been not only utilized in the heat pump system but also applied in many energy cycles $^{1}$. And it is known that lubricant is significant for the compressor. It can lubricate the frictional parts, prevent gas leakage, and cool down the mechanical pieces heated by friction ${ }^{2}$. However, a certain part of the lubricant circulates with the flow of refrigerant in the heat pump $\mathrm{cycle}^{3)}$. The interaction between lubricant and refrigerant would raise a considerable impact on the system performance.

In the past, researchers have investigated the properties of lubricants exhaustively. Early in 1985, Nakamura ${ }^{4}$ invented use an oil separator to improve compressor lubrication and reduce circulation time by discharging the lubricant oil continuously from the compressor. Conde ${ }^{5)}$ made an appraisal of the existing method till 1996, which was used to estimate of thermophysical properties of lubricating oils and their solutions with refrigerants. Lottin $^{6}$ made research by modeling on refrigeration system using a mixture of R410A and polyol ester(POE) to analyze the effects of lubricant oil with an increasing amount. The results showed that these effects for COP and evaporator power become important when the quantity of lubricant oil blended into the refrigerant above $0.5 \%$. Then $\mathrm{he}^{7)}$ continued to study the effect of oils during the working periods of the heat exchangers. When the concentration of oil is $0.1 \%$ in particular, the heat transfer coefficient of the evaporator had a slight improvement. However, with the increase of oil in the heat pump cycle, a progressive trend was caused by the performance of the mixture fluid. An overview investigation about the heat transfer performance between oils and conventional refrigerants as well as $\mathrm{CO}_{2}$ was carried out by Wang ${ }^{8)}$. The conclusion pointed out that the effect of lubricants on heat transfer coefficient is quite complex, which might be positive or negative for the heat transfer performance depending on the lubricant mass fraction, the viscosity, the surface tension, and the like.

Facing the problems of global warming and the damage of the ozonosphere, the companies are striving to make the products more efficient and environmentally by study refrigerants ${ }^{9)}$ and compressors. With the development of refrigerants and compressors, the research about lubricants is also continuing. For a further study about the influence of lubricants on the heat pump performance, this paper would discuss the thermal dynamic properties of the lubricants for the application of the heat pump cycle, and study the role of lubricant oils through two aspects: the influence on the compressor performance, and the interaction with refrigerants. Then the effect of the lubricants on the whole system would be concluded finally.

\section{Properties of lubricants}

Several characteristics need to be aware when selecting the lubricant for refrigeration or heat pump cycle: thermal stability, chemical stability, viscosity, and refrigerant/oil solubility. Thanks to these, the choice of lubricant depends on the system, the refrigerant, and the type of application. 


\subsection{Types of lubricants}

The categories of lubricants for heat pump or refrigeration are primary mineral oils and synthetic oils.

Mineral oils, consisting of hydrocarbons without wax, are a kind of suitable lubricant for the heat pump compressor because of their superior fluidity at the lowtemperature range, especially suited for mixing with $\mathrm{CFC}$, HCFC, and ammonia.

Synthetic oils, a combination of artificial chemical compounds, are widely applied in extreme temperature range as the substitute for petroleum-refined oils. The types of them usually include Alkyl Benzene oils (AB), Poly Alpha Olefins (PAO), Poly Alkylene Glycols (PAG), Polyol Ester oils (POE), and Polyvinyl Ether (PVE).

\subsection{Viscosity}

There are two basic roles the oil plays inside the compressor: one is to lubricant the mechanical pieces; the other is to reduce heat leakage. The research ${ }^{10)}$ pointed out that oil can absorb about $5 \sim 10 \%$ heat loss during the operation of the compressor. And the viscosity is considered one of the most important characteristics for the role of lubricant. The thickness of lubricant film is a function of the viscosity, which has a fundamental impact on the compressor performance and reliability ${ }^{11)}$. High viscosity would lead to a drop in the compressor efficiency, while the rotating parts of the compressor might be wear and ran out faster because of the lubricant with low viscosity $^{12)}$.

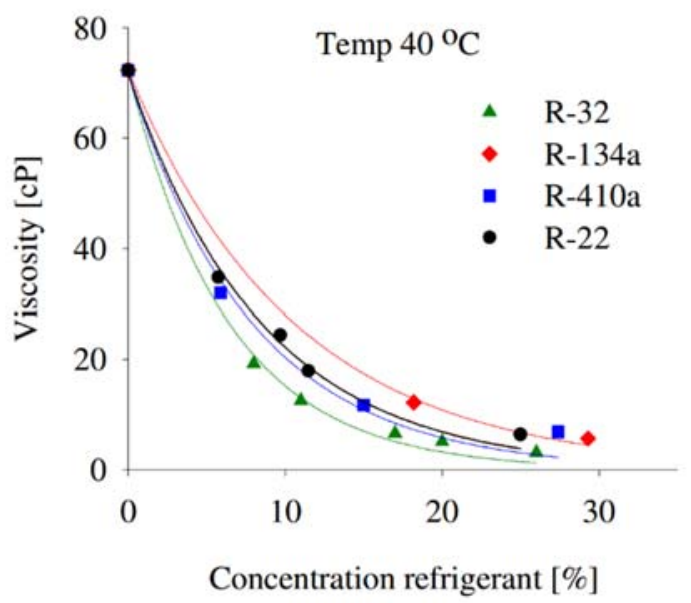

Fig. 1: Viscosity change with the concentration of refrigerants.

Because of the diluting by the refrigerant, the increase of temperature, and the decrease of pressure, the viscosity of oils would be dropdown. Fig. $1^{13)}$ shows the trend of viscosity change by adding various refrigerants from 0 to $30 \%$ into the oil. Lin and Kedzierski ${ }^{14)}$ predicted the viscosity of a pure POE lubricant by the nonequilibrium molecular dynamic simulation. The result adequately described the viscosity in different temperature and pressure range with the comparison of experimental data. To work in a heat pump system properly, the viscosity of lubricant must be maintained high enough, while it can be decreased by the refrigerant and make the oil remain liquid to flow back to the compressor through the cycle.

\subsection{Compressibility and density}

The compressibility of lubricants, which deeply involves the dimension of the peak in the pressure distribution, is a significant factor to reduce the stress of mechanical pieces and improve the life of bearing components $^{15}$. From an investigation by Jacobson ${ }^{16)}$, a great reduction of the compressibility occurred when adding about $20 \%$ by weight of R134a into SL68 POE at the pressure condition of $300 \mathrm{MPa}$, which almost about $1 / 3$ of pure oil. Bair et al. ${ }^{17)}$ reviewed the researches about the compressibility of oil/refrigerant and highlight the methods to predict and control the friction of compressor by the compressibility of oil/refrigerant mixtures.

The density of lubricants, as important as the viscosity, inherently affects the lubricant hydrodynamics ${ }^{18)}$. The density is also a fundamental parameter to predict or simulate the properties of oil/refrigerant mixtures. A group of experimental data, which summarized the density and viscosity of lubricant PEC6, was measured by Lin and Kedzierski ${ }^{14)}$. They pointed out that the density of lubricants can be predicted with high accuracy by standard molecular dynamic simulation.

\subsection{Solubility with refrigerants}

The solubility of the refrigerant in oil is significant because the lubricant would go through the circulation and come back to the compressor with refrigerant ${ }^{19)}$. Especially it has a considerable effect on the evaporator performance when under the same working condition ${ }^{20)}$. Besides, the refrigerant, as an effective solvent, also change the viscosity and density of the lubricant more than temperature alone ${ }^{21)}$.

\begin{tabular}{|c|c|c|c|c|c|}
\hline & $\begin{array}{c}\text { Mineral Oils } \\
\& \text { PAOs }\end{array}$ & Alkyl benzene & POE & PAG & PVE \\
\hline HCFC & & & & $\begin{array}{c}\text { Not } \\
\text { Recommended }\end{array}$ & $\begin{array}{c}\text { Not } \\
\text { Recommended }\end{array}$ \\
\hline HFC & $\begin{array}{c}\text { Not } \\
\text { Recommended }\end{array}$ & $\begin{array}{c}\text { Only in } \\
\text { special cases }\end{array}$ & & $\begin{array}{l}\text { special design } \\
\text { considerations }\end{array}$ & \\
\hline HC & & & & & \\
\hline $\mathrm{NH}$ & & & & & $\begin{array}{c}\text { Not } \\
\text { Recommended }\end{array}$ \\
\hline $\mathrm{CO}_{2}$ & $\begin{array}{c}\text { Not } \\
\text { Recommended }\end{array}$ & $\begin{array}{c}\text { Not } \\
\text { Recommended }\end{array}$ & $50 / 50$ & & $50 / 50$ \\
\hline \begin{tabular}{|c|} 
HFO \\
Based
\end{tabular} & $\begin{array}{c}\text { Not } \\
\text { Recommended }\end{array}$ & Probably not & $\begin{array}{c}\text { Under } \\
\text { development }\end{array}$ & $\begin{array}{c}\text { Under } \\
\text { development }\end{array}$ & Maybe? \\
\hline
\end{tabular}

Fig. 2: Lubricant option with different types of refrigerants.

Fig. $2^{21)}$ takes a look at the lubricant options for refrigerant chemistry. These options have not changed over the last several years. Some of this is due to the limitation of certain rules, while others are limited to certain parameters that might be re-test to get a better understanding of acceptability.

The solubility of lubricants with refrigerants can make 
a progress for not only the system efficiency but also the energy consumption. It demands a molecular thermodynamic model to predict the characteristics of oil/refrigerant mixture appropriately ${ }^{22)}$. A group of statistical mechanical equations was developed by Zolfaghari and Yousefi ${ }^{23)}$ to calculate the volumetric properties of sixteen mixtures of lubricants and refrigerants, and the result showed good harmony with the literature. The solubilities of low global warming potential refrigerants in commercial POE lubricants, including R1234ze(E), R1234yf, RE170, R600a, and R744, were simulated by Fouad and Vega with a molecular model ${ }^{24}$. An experimental measurement about the solubilities and diffusivities of R1234yf and R1234ze(E) in VG32 POE oil was also presented by Morais et $\mathrm{a}^{25)}$.

\section{Influence of lubricants}

The advantages and disadvantages of lubricant in heat pump/refrigeration are introduced from a different direction in this part, which would point out that lubricant is a considerable parameter for the system performance.

\subsection{Impact on refrigerants}

Mixing with refrigerant would cause the viscosity reduction of lubricant, the heat transfer performance of refrigerant will decrease as well.

The influence of PAG on a water-cooled gas cooler was examined by $\mathrm{Dai}^{26)}$ with different oil concentrations, tube diameters, operation pressure, mass flow rate, and water inlet temperature. The result showed a negative effect of the oil, and it became significant under several conditions: decreasing of the tube diameter, approaching the critical pressure, and a high flow rate of the secondary fluid.

The reduction of gas cooler thermal effectiveness with the increase of oil concentration in different hydraulic diameters is illustrated in Fig. ${ }^{26}$. The negative effect is more obvious, while the hydraulic diameter of the gas cooler is designed smaller.

Besides, with the increase of lubricant concentration, the pressure drop in the condenser would become worse. Fig. $4^{27)}$ shows the change of the frictional pressure drop with different qualities of lubricant. The decreasing tendency of the pressure drop may be caused by the transition from turbulent flow to laminar flow.

From the discussion above, it can be concluded that the performance of refrigerant would be repressed with an increasing concentration of lubricant. However, it cannot decide the influence on the efficiency of the heat pump system for this reason only since the lubricant has a positive effect on compressor performance, especially for the prevention of gas leakage that is the main reason for a heat pump system to cause the environmental impact with refrigerants ${ }^{28)}$.

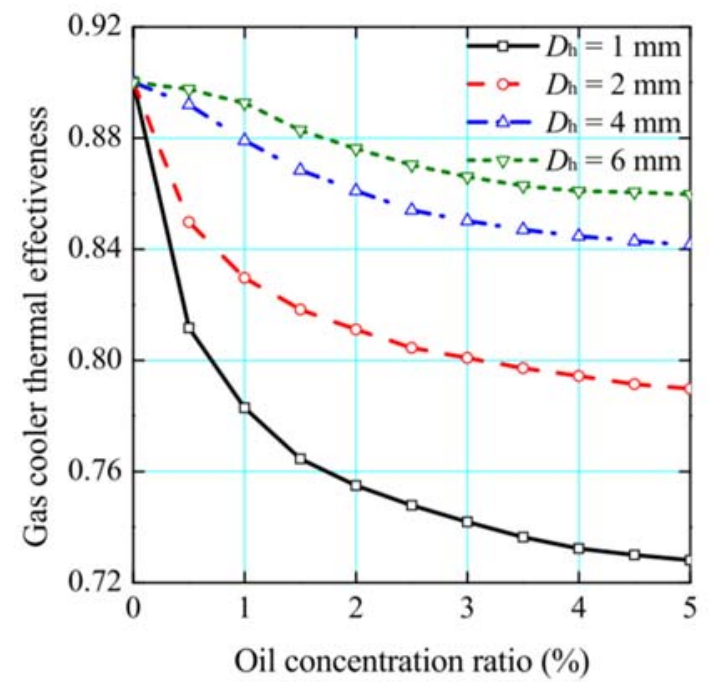

Fig. 3: Influence of lubricant concentration on the gas cooler thermal effectiveness with different hydraulic diameters.

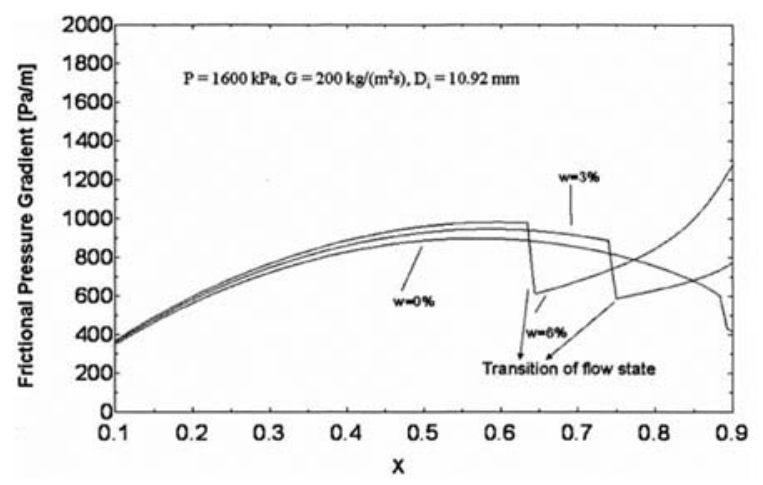

Fig. 4: Friction pressure change with different qualities.

\subsection{Impact on compressor}

As mention in the beginning, the advantages of lubricant are the reduction of damage and heat losses caused by friction and the prevention of gas leakage at the compressor, which makes progress on compressor operation. Especially in the application of a large scale, such as supermarket heat pump systems, the charge amount of refrigerants may require as 2 to 3 times of the cooling load ${ }^{29)}$. A number amount of leakage (about $20 \%$ ) may occur from the installing processes or during operation $^{30,31)}$, which would drop down the performance of the compressor and cause an environmental impact ${ }^{32)}$.

In the research of Afshari33), the effects of lubricant mixing with R404a on reciprocating compressors in airwater heat pumps are analyzed.

The impact of the charge amount of refrigerant in the compressor power consumption with various oil viscosity (from low viscosity to high viscosity: SL22, SL68, SL220) is reported in Fig. ${ }^{33)}$. As the charge amount of refrigerant increases, while it means the lubricant concentration decrease, the power consumption of the compressor increases simultaneously. And the differences 
appear more obvious when the lubricant with lower viscosity is applied.

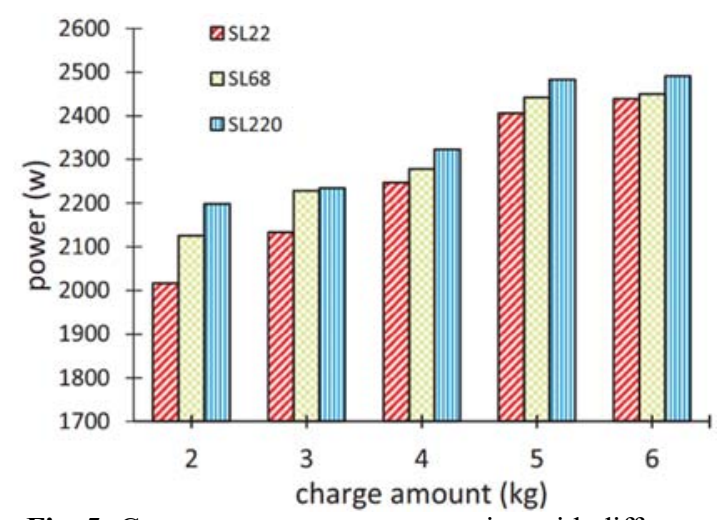

Fig. 5: Compressor power consumption with different lubricants.

The second law and isentropic efficiency of the compressor versus the charge amount of refrigerant are also shown in Fig. $6^{33)}$. The tendency of both reported efficiencies falls gradually by increasing the amount of refrigerant as same as that the lubricants are diluted. That verifies again that the compressor performs better when the concentration of lubricant is higher.

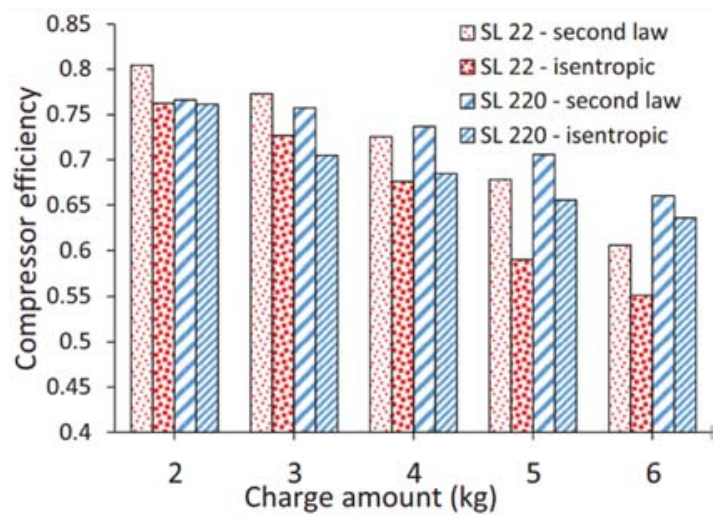

Fig. 6: Second law and isentropic efficiency of the compressor with two kinds of lubricants.

Furthermore, it can be recognized that lubricants with less viscosity present less power consumption and higher second law efficiency. SL22 shows the maximum exergy efficiency in comparison with other lubricants.

\subsection{Impact on the whole system}

Compared with the mass fraction of refrigerant, lubricant shows less influence on the COP and exergy of the heat pump system. But when the charge amount of refrigerant maintains in the same value and other conditions such as temperature in the evaporator or water flow rate in the condenser are changed individually, the result shows the same relationship between the viscosity of the lubricant and the COP of the system as Fig. 7 and Fig. $8^{33)}$. That is the system has a better performance with lower oil viscosity.
Thundermore, the mass flow, which is one of the important factors to affect the performance of the heat exchanger and the heat pump system, is controlled by the compressor power and the refrigerant mass ${ }^{34)}$. And lubricants have a significant influence on the two factors.

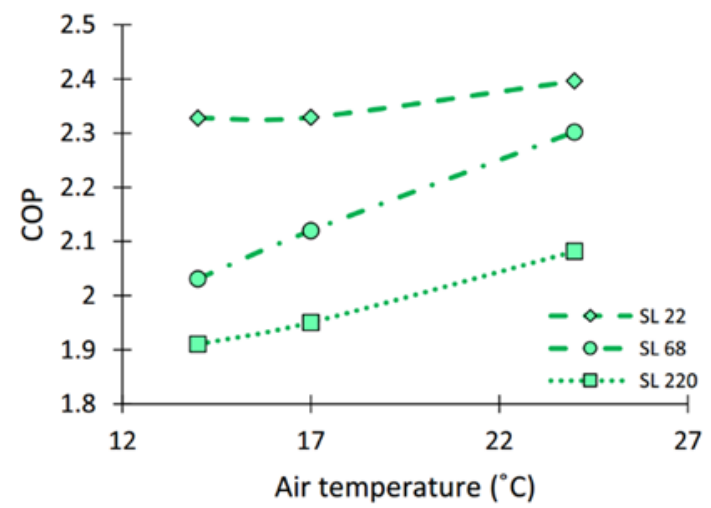

Fig. 7: Influence of lubricant on the COP with different inlet temperatures of the evaporator ${ }^{33)}$.

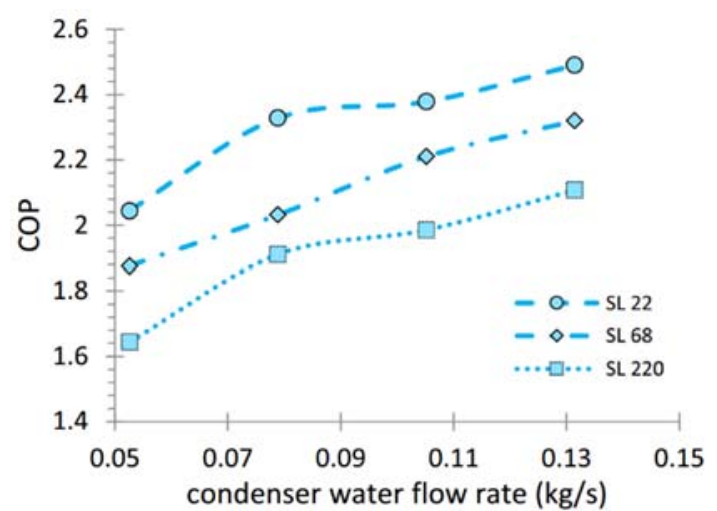

Fig. 8: Influence of lubricant on the COP with different water flow rates of the condenser ${ }^{33)}$.

\section{Conclusion}

The role that playing by the lubricants in the heat pump system is introduced in this paper. The viscosity, compressibility and density, and solubility with refrigerant are the important properties of lubricants. As mixing the refrigerant and lubricant, the viscosity of lubricant falls with the dilution of refrigerant, while the amount of lubricant simultaneously decreases the heat transfer coefficient of the refrigerant. The lubricant with lower viscosity performs better in the improvement of efficiency and the reduction of power consumption in the compressor in the same experimental condition.

The studies of lubricants are special in the different viscosity, refrigerant, compressor, and application. But it shows some general effects of lubricants on the system performance, which would provide a piece of helpful information for the investigation of next-generation lubricants . 


\section{References}

1) M. Muslim, M.I. Alhamid, Nasruddin, and B. Ismoyo, "Analysis of the scroll compressor changing into an expander for small scale power plants using an organic rankine cycle system," Evergreen, 7 (4) 615620 (2020). doi:10.5109/4150515.

2) G. Valenti, S. Murgia, G. Contaldi, and A. Valenti, "Experimental evidence of the thermal effect of lubricating oil sprayed in sliding-vane air compressors," Case Stud. Therm. Eng., 4 113-117 (2014).

3) M. Youbi-Idrissi, and J. Bonjour, "The effect of oil in refrigeration: current research issues and critical review of thermodynamic aspects," Int. J. Refrig., 31 (2) $165-179$ doi:10.1016/j.jirefrig.2007.09.006.

(2008).

4) T. Nakamura, "Heat pump having improved compressor lubrication," (1985).

5) M.R. Conde, "Estimation of thermophysical properties of lubricating oils and their solutions with refrigerants: an appraisal of existing methods," Appl. Therm. Eng., 16 (1) 51-61 (1996).

6) O. Lottin, P. Guillemet, and J.-M. Lebreton, "Effects of synthetic oil in a compression refrigeration system using r410a. part i: modeling of the whole system and analysis of its response to an increase in the amount of circulating oil," Int. J. Refrig., 26 (7) 772-782 (2003).

7) O. Lottin, P. Guillemet, and J.-M. Lebreton, "Effects of synthetic oil in a compression refrigeration system using r410a. part ii: quality of heat transfer and pressure losses within the heat exchangers," Int. J. Refrig., 26 (7) 783-794 (2003).

8) C.C. Wang, A. Hafner, C.S. Kuo, and W. Der Hsieh, "An overview of the effect of lubricant on the heat transfer performance on conventional refrigerants and natural refrigerant r-744," Renew. Sustain. Energy Rev., $16 \quad$ (7) 5071-5086 (2012). doi:10.1016/j.rser.2012.04.054.

9) A. Pal, K. Uddin, K. Thu, and B.B. Saha, "Environmental assessment and characteristics of next-generation refrigerants," Evergreen, 5 (2) 58-66 (2018). doi:10.5109/1936218.

10) A.T. Prata, and J.R. Barbosa Jr, "Role of the thermodynamics, heat transfer, and fluid mechanics of lubricant oil in hermetic reciprocating compressors," Heat Transf. Eng., 30 (7) 533-548 (2009).

11) S. Bair, "The viscosity at the glass transition of a liquid lubricant," Friction, 7 (1) 86-91 (2019). doi:10.1007/s40544-018-0210-1.

12) E. Navarro, J.M. Corberan, I.O. Martínez-Galvan, and J. Gonzalvez, "Oil sump temperature in hermetic compressors for heat pump applications," Int. J. Refrig., 35 (2) 397-406 (2012).
13) R. Tuomas, "Properties of oil and refrigerant mixtures: lubrication of ball bearings in refrigeration compressors," (2006).

14) L. Lin, and M.A. Kedzierski, "Density and viscosity of a polyol ester lubricant: measurement and molecular dynamics simulation," Int. J. Refrig., 118 188-201 (2020). doi:10.1016/j.ijrefrig.2020.07.004.

15) B.J. Hamrock, B.J. Schmid, and B.O. Jacobson, "Fundamentals of fluid film lubrication," CRC Press, 2004.

16) B. Jacobson, "A new high-pressure chamber for lubricant investigations," Proc. ITC Nagasaki 2000, 1199-1202 (2001).

17) S. Bair, M. Baker, and D.M. Pallister, "Revisiting the compressibility of oil/refrigerant lubricants," $J$. Tribol., 139 (2) (2017).

18) J.P. Ewen, C. Gattinoni, F.M. Thakkar, N. Morgan, H.A. Spikes, and D. Dini, "A comparison of classical force-fields for molecular dynamics simulations of lubricants," Materials (Basel)., 9 (8) 651 (2016).

19) K. Takigawa, S.I. Sandler, and A. Yokozeki, "Solubility and viscosity of refrigerant/lubricant mixtures : hydrofluorocarbon/alkylbenzene systems," Int. J. Refrig., 25 1014-1024 (2002).

20) M. Youbi-Idrissi, J. Bonjour, C. Marvillet, and F. Meunier, "Impact of refrigerant-oil solubility on an evaporator performances working with r-407c," Int. $J$. Refrig., 26 (3) 284-292 (2003).

21) J. Karnaz, and C. Seeton, "Evaluation of lubricant properties and refrigerant interaction," (2018).

22) K.N. Marsh, and M.E. Kandil, "Review of thermodynamic properties of refrigerants + lubricant oils," Fluid Phase Equilib., 33 (40) no-no (2010). doi:10.1002/chin.200240299.

23) H. Zolfaghari, and F. Yousefi, "Thermodynamic properties of lubricant/refrigerant mixtures using statistical mechanics and artificial intelligence," Int. $\begin{array}{lllll}\text { J. } & \text { Refrig., } & \mathbf{8 0} & 130-144 & \text { (2017). }\end{array}$ doi:10.1016/j.ijrefrig.2017.04.025.

24) W.A. Fouad, and L.F. Vega, "Molecular modeling of the solubility of low global warming potential refrigerants in polyol ester lubricants," Int. J. Refrig., 103 (2019). doi:10.1016/j.jirefrig.2019.04.004.

25) A.R.C. Morais, L.D. Simoni, A.M. Scurto, and M.B. Shiflett, "Solubility and diffusivity of hydrofluoroolefin refrigerants in a polyol ester lubricant," Ind. Eng. Chem. Res., 59 (13) 6279-6287 (2020). doi:10.1021/acs.iecr.9b06821.

26) B. Dai, M. Li, C. Dang, W. Yu, and Y. Ma, "Effects of lubricating oil on thermal performance of watercooled carbon dioxide gas cooler," Appl. Therm. Eng., 80 288-300 (2015).

27) B. Shen, and E.A. Groll, "A critical review of the influence of lubricants on the heat transfer and pressure drop of refrigerants-part ii: lubricant 
influence on condensation and pressure drop," HVAC\&R Res., 11 (4) 511-526 (2005).

28) M.T. Kibria, M.A. Islam, B.B. Saha, T. Nakagawa, and S. Mizuno, "Assessment of environmental impact for air-conditioning systems in japan using HFC based refrigerants," Evergreen, 6 (3) 246-253 (2019). doi:10.5109/2349301.

29) F. Poggi, H. Macchi-Tejeda, D. Leducq, and A. Bontemps, "Refrigerant charge in refrigerating systems and strategies of charge reduction," Int. J. $\begin{array}{lllll}\text { Refrig., } & 31 \quad \text { (3) } \quad 353-370 \quad \text { (2008). }\end{array}$ doi:10.1016/j.ijrefrig.2007.05.014.

30) S.A. Tassou, and I.N. Grace, "Fault diagnosis and refrigerant leak detection in vapor compression refrigeration systems," Int. J. Refrig., 28 (5) 680-688 (2005). doi:10.1016/j.ijrefrig.2004.12.007.

31) C. Francis, G. Maidment, and G. Davies, "An investigation of refrigerant leakage in commercial refrigeration," Int. J. Refrig., 74 10-19 (2017). doi:10.1016/j.ijrefrig.2016.10.009.

32) M.A. Islam, A. Pal, K. Thu, and B.B. Saha, "Study on performance and environmental impact of supermarket refrigeration system in japan," Evergreen, 6 (2) 168-176 (2019).

33) F. Afshari, O. Comakli, A. Lesani, and S. Karagoz, "Characterization of lubricating oil effects on the performance of reciprocating compressors in airwater heat pumps," Int. J. Refrig., 74 505-516 (2017).

34) M.I. Alhamid, N. Nasruddin, Budihardjo, E. Susanto, T.F. Vickary, and M. Arif Budiyanto, "Refrigeration cycle exergy-based analysis of hydrocarbon (r600a) refrigerant for optimization of household refrigerator," Evergreen, 6 (1) 71-77 (2019). doi:10.5109/2321015. 